\title{
2020PMD, 30-years of Translational Mobility Medicine at the time of COVID-19 outbreak: Last-minute forewords from the editor
}

\author{
Ugo Carraro $(1,2)$ \\ (1) Department of Biomedical Sciences, University of Padova, Italy (2) Armando \& Carmela \\ Mioni-Carraro Foundation for Translational Myology Padova, Italy \\ This article is distributed under the terms of the Creative Commons Attribution Noncommercial License (CC BY-NC 4.0) which permits \\ any noncommercial use, distribution, and reproduction in any medium, provided the original author(s) and source are credited.
}

\begin{abstract}
In the autumn of 2019, the organizers of the 2020 Padua Muscle Days planned an intense program, which was to be held from March 18 to March 21, 2020. The program included eight Scientific Sessions to occur over three full days at either Padova University or the Hotel Augustus on Euganei Hills (Padova), Italy. Abruptly, however, in early January the Coronavirus COVID-19 outbreak started in China and changed the world perspectives and expectations. In Italy, it started in Lombardy and Veneto, two main industrial areas of the country with intense connections and interchanges of people and commercial activities with China. Indeed, the virus was first isolated from a couple of Chinese tourists, who inadvertently incubated the infection during their visit to many towns in Italy. Within the following two weeks, the epidemic had the first Italian cases and victims in an area south of Milan and in a Village of the Euganei Hills (Vo Euganeo, Padova). The village was immediately quarantined, but it was too late. The virus had escaped the area. Thus, it was a mandatory, though difficult decision (made even before the Italian National Government posted rules to be followed to decrease spread of the infection), to post-pone the Padua Muscle Days meeting from 18-21 March, 2020 to 25-28 November, 2020. Luckily, the vast majority of organizers, chairs, speakers, and attendees accepted the decision and have assured their presence in late November, despite the coincidence with the Thanksgiving holiday in the US. Currently, the only changes in the program are the new dates; however, it is difficult to forecast the future. Anyhow, the rationale of the decision to post-pone 2020PMD was reinforced by the actions of many organizers of international events. One of the most recent examples is the March 6, 2020 decision of the leaders of the Experimental Biology Host Societies to cancel Experimental Biology (EB) 2020, set to take place April 4-7 in San Diego, California, USA. All these active civil responses to world dangers are mandatory to avoid those military responses that are easy to start, but provide the worst results. How do we not lose half of the 2020 year? The option is to try to achieve some of the goals of the meeting by long-distance communications. Thus, the Collection of Abstracts will be, as originally planned, e-published in this 30(1) 2020 Issue of the European Journal of Translational Myology (EJTM) together with the many EJTM Communications submitted by speakers and attendees of the 2020PMD. We may also start the process that will implement EMMA, the European Mobility Medicine Association, by circulating a proposal and inviting comments.
\end{abstract}

Key Words: Padua Muscle Days, Translational Mobility Medicine, COVID-19 outbreaks, forewords of the editor

Eur J Transl Myol 30 (1): 1-2, 2020

\begin{abstract}
A series of meetings concerning muscle biology, physiology, medicine and rehabilitation, called Padua Muscle Days (PMD), were initiated more than 30 years ago and have continued through the present. PMD provided a forum for a core community of Myologists, who also accepted the burden of organizing and managing a new journal they titled Basic and Applied
\end{abstract}

Myology (which was renamed European Journal of Translational Myology in 2010). Recognizing the inextricable mutual dependence of muscle and nervous tissues, muscle function and mobility, aging and mobility, pain and mobility, diseases and mobility, the journal editors extended the journal's topics to include many entangled sports and medical-related sub-fields. Always the prime interest was on designing, developing 
and implementing basic research activities and trials having common goals: to help prevent mobility disorders and/or to manage or rehabilitate young adults and elderly persons suffering from mobility disorders. That is, the journal founders sought to enhance Translational Mobility by promoting research and development of physical, chemical, biological, and technological approaches to abatement of mobility issues. We may call this Translational Mobility Medicine, a unifying name covering the core concepts of the journal interests. The organizers of the 2020Padua Muscle Days implemented an intense program that was to be held from March 18 to March 21, being three full days of communication and community to be spent either in Padova University or in the Hotel Augustus on Euganei Hills (Padova), Italy. ${ }^{1}$

Abruptly, however, the Coronavirus COVID-19 outbreak, which began in China, quickly spread and changed the world perspectives and expectations. In Italy the virus was first detected in Lombardy and Veneto, two main industrial areas of the country with intense connections and interchanges of people and commercial activities with China. Indeed, the virus was first isolated from a couple of Chinese tourists harboring the infection, who were visiting many towns in Italy. Within a week, the epidemic affected the first Italian victims in an area south of Milan and in a village of the Euganei Hills (Vo Euganeo, Padova). The village was immediately quarantined, but it was too late. The virus was spreading through the area. Thus, it was a mandatory, though difficult decision (made even before the Italian National Government posted rules to be followed to decrease the spread of infection) to post-pone the Padua Muscle Days from 18-21 March, 2020 to 25-28 November, 2020. Luckily, the vast majority of organizers, chairs, speakers and attendees accepted the decision and have assured their presence in late November, despite the coincidence with the U.S. national holiday of Thanksgiving, a day marked by religious observances and a traditional meal including turkey. Indeed, it is held in the US on the fourth Thursday of November. At present, the only changes in the November PMD Program are the new dates. ${ }^{2}$ Obviously, it is difficult to forecast the future and we expect there will be some minor changes for November. Let us stress that the decision was to post-pone, NOT to cancel, the 2020 PaduaMuscleDays. Anyhow, the rationale of the decision was soon reinforced by the restrictions implemented by the Italian Regional and National governments and by the actions of many organizers of other international events. One of the more recent cancellations was released on March 6, 2020: the decision of the leaders of the Experimental Biology host societies to cancel Experimental Biology (EB) 2020, set to take place April 4-7 in San Diego, California, USA. They said to have made the decision after thoughtful deliberations due to the fears of spreading the virus. How do we not lose half of the 2020 year? The option is to try to achieve some of the goals of the 2020 PMD meeting by long-distance communications. In an era of infection by a very diffusive virus, long-distance communication is the safer way to maintain personal and international relations. Thus, the Collection of Abstracts will be, as planned, e-published in this 30(1) 2020 Issue of the European Journal of Translational Myology (EJTM) together with the many EJTM Communications submitted by Speakers and Attendees of the 2020PMD. We may also start the process that will implement EMMA, the European Mobility Medicine Association, by circulating proposals and comments. Active civil responses to world dangers are mandatory to avoid military responses, which are easy to start, but usually provide the worst results. Anyhow, see you soon by Internet-communication and finally November 25-28 for the 2020 Padua Muscle Days in the Euganei Hills and Padua University (Padova) Italy.

\section{List of acronyms}

EJTM - European Journal Translational Myology

PMD - Padua Muscle Days

COVID-19 - Coronavirus disease 2019

WHO - World Health Organization

EMMA - European Mobility Medicine Association

\section{Acknowledgments}

The authors thanks Organizers, Chairs, Speakers and Attendees of the 2020PMD, who supported the hard decision to postpone 2020PMD to 25-28 November, 2020.

\section{Funding}

Supported by Armando \& Carmela Mioni-Carraro Foundation for Translational Myology Padova, Italy

\section{Conflict of Interest None.}

\section{Ethical Publication Statement}

We confirm that we have read the Journal's position on issues involved in ethical publication and affirm that this report is consistent with those guidelines.

\section{Corresponding Author}

Ugo Carraro, Department of Biomedical Sciences, University of Padova, Via Ugo Bassi, 58/B 35131 Padova Italy. ORCID iD: 0000-0002-0924-4998

Email: ugo.carraro@unipd.it

\section{References}

1. Carraro U. Thirty years of translational research in Mobility Medicine: Collection of Abstracts of the 2020 Padua Muscle Days. Eur J Transl Myol 2020;30:3-47. Doi: 10.4081/ejtm.2019.8826

2. Link to: pagepressjournals.org/index.php/bam/Ann ouncement/view/317

Submitted: March 10, 2020 Accepted for publication: March 10, 2019 